\title{
Klotho and vitamin D in multiple sclerosis: an Italian study
}

\author{
Concetta Scazzone ${ }^{1}$, Luisa Agnello ${ }^{1}$, Bruna Lo Sasso ${ }^{1}$, Paolo Ragonese², Giulia Bivona ${ }^{1}$, \\ Sabrina Realmuto², Giorgia Iacolino ${ }^{1}$, Caterina Maria Gambino ${ }^{1}$, Chiara Bellia ${ }^{1}$, Giuseppe Salemi², \\ Marcello Ciaccio ${ }^{1,3}$
}

\begin{abstract}
${ }^{1}$ Department of Biomedicine, Neuroscience, and Advanced Diagnostics, Institute of Clinical Biochemistry, Clinical Molecular Medicine, and Laboratory Medicine, University of Palermo, Palermo, Italy

${ }^{2}$ Department of Experimental Biomedicine and Neuroscience, University of Palermo, Palermo, Italy

${ }^{3}$ Department of Laboratory Medicine, University-Hospital, Palermo, Italy
\end{abstract}

Submitted: 21 March 2019

Accepted: 1 May 2019

Arch Med Sci 2020; 16 (4): 842-847

DOI: https://doi.org/10.5114/aoms.2019.86969

Copyright $\odot 2019$ Termedia \& Banach

\section{Abstract}

Introduction: Low vitamin D levels have been recognised as an important risk factor for autoimmune diseases, including multiple sclerosis (MS). MS is a multifactorial disease, the pathogenesis of which contributes both to genetic and environmental factors. Polymorphisms in genes codifying molecules involved in vitamin D homeostasis have been associated with hypovitaminosis D. However, the influence of polymorphisms of Klotho, which codify a protein with a pivotal role in vitamin D metabolism, have never been investigated. The aim of this study was to evaluate the association among genetic variants of Klotho, namely rs 1207568 and rs9536314, serum $25(\mathrm{OH}) \mathrm{D}_{3}$ levels, and multiple sclerosis (both risk and disease progression).

Material and methods: 107 patients with MS and 133 healthy controls were enrolled in this study. Serum $25(\mathrm{OH}) \mathrm{D}_{3}$ levels and genotyping of Klotho SNPs were evaluated in all participants by high-performance liquid chromatography and real-time polymerase chain reaction, respectively.

Results: Allelic and genotypic frequencies did not differ between patients and controls. Concerning rs1207568, we found a trend toward lower serum $25(\mathrm{OH}) \mathrm{D}_{3}$ levels in MS patients with A allele (mutant), both in heterozygosis $(\mathrm{AG})$ and in homozygosis (AA), in comparison to MS patients with $G$ allele in homozygosis (GG) (AG + AA $20.5 \pm 6.3 \mu \mathrm{g} / \mathrm{l}$; GG $22.5 \pm 7.5 \mu \mathrm{g} / \mathrm{l}, p=0.07$ ). Conclusions: Our findings did not identify a role of Klotho in the genetic susceptibility to MS.

Key words: vitamin D, Klotho, genetic, multiple sclerosis.

\section{Introduction}

Multiple sclerosis (MS) is a chronic inflammatory, autoimmune disease of the central nervous system (CNS) characterised by demyelination and axonal degeneration. It is the commonest non-traumatic disabling disease affecting young adults [1]. MS is generally recognised as a T-cell mediated disease, but the exact underlying causes are not completely understood. It is currently considered a very heterogeneous disorder in which both genetic-susceptibility and environmental exposures are

\author{
Corresponding author: \\ Prof. Marcello Ciaccio \\ MD, PhD \\ Department \\ of Biomedicine, \\ Neuroscience and \\ Advanced Diagnostics \\ Institute of Clinical \\ Biochemistry, \\ Clinical Molecular \\ Medicine, and \\ Laboratory Medicine \\ University of Palermo \\ Via Del Vespro 129 \\ 90127 Palermo, Italy \\ E-mail: marcello.ciaccio@ \\ unipa.it
}


strongly implicated in the activation of T cells and MS-pathogenesis [2]. Current research is focused on the identification of risk factors. In the last decades, a role of hypovitaminosis $D$ has emerged [3]. Since the discovery of vitamin $D$ immunomodulatory function, vitamin $D$ has been proposed as a serum biomarker in several clinical conditions, including neurodegenerative disorders, along with inflammatory and cardiovascular markers [4-16].

It is well recognised that patients affected by MS usually have lower vitamin D levels than the general population [17]. However, the question that needs to be addressed is whether low vitamin D levels contribute to MS pathogenesis or if they stem from it. Preliminary hypothesis supported that hypovitaminosis $D$ is the result of inadequate sun exposure due to the physical disability related to MS [18], but a great deal of evidence from epidemiological and experimental studies supports the pathogenic role of vitamin D [19-21]. On the one hand, prospective epidemiological studies have shown that elevated serum vitamin $D$ levels are associated with a decreased risk for developing MS later in life among healthy young adults [22] and with reduced clinical activity in established MS patients [23]; on the other hand, experimental studies revealed that the biologically active form of vitamin $D$, namely 1,25-dihydroxy-vitamin $\mathrm{D}_{3}\left[1,25(\mathrm{OH})_{2} \mathrm{D}_{3}\right]$, exerts an immunomodulatory action, controlling both adaptive and innate immunity, as well as a neuroprotective role [10, 24-28].

A lot of evidence supports the hypothesis that low vitamin $D$ levels are the result of both environmental and genetic factors [22]. Concerning the role of genetics, Genome Wide Association Studies (GWAS) have identified variants in genes codifying molecules involved in vitamin D metabolism that have been confirmed in gene-candidate studies [29-32]. Among regulators of vitamin D metabolism, Klotho plays a prominent role.
Klotho is a protein casually identified by Kuro-o et al. [33] in 1997 during experiments on transgenic mice. Klotho is a transmembrane glycoprotein with a large extracellular domain and a short cytosolic domain $(\approx 10 \mathrm{aa}$ ). It exists in two isoforms with distinct biological function: transmembrane and soluble. The latter derives from alternative splicing or proteolytic cleavage of transmembrane Klotho by membrane protease (ADAM 10 and 17). Soluble Klotho is detectable in blood, urine, and cerebrospinal fluid (CSF) [34], and it acts as a humoral factor influencing several cellular processes $[35,36]$. Transmembrane Klotho functions as a co-receptor for fibroblast growth factor-receptor (FGF-R) and provides selective binding affinity to FGF-23. The complex Klotho/FGF-R/FGF-23 is involved in vitamin $D$ homeostasis [37]. In particular, vitamin $\mathrm{D}$ and Klotho biological functions are highly intertwined because vitamin $D$ controls the expression of Klotho, and Klotho feeds back to inhibit the $1 \alpha$-hydroxylase (CYP27B1), which converts 25 -hydroxy-vitaminD $3\left[25(\mathrm{OH}) \mathrm{D}_{3}\right]$ to the biologically active form, $1-25(\mathrm{OH})_{2} \mathrm{D}_{3}$, and to induce the activity of the 24-hydroxylase (CYP24A1), which converts both $25(\mathrm{OH}) \mathrm{D}_{3}$ and $1-25(\mathrm{OH})_{2} \mathrm{D}_{3}$ in 24-hydroxylated products targeted for excretion (Figure 1) [35, 38]. Thus, genetic variants of Klotho associated with an alteration of its levels or its biological function could lead to hypovitaminosis D and, consequently, to an increased risk of several pathological conditions. The aim of our study was to evaluate the relationship among Klotho genetic variants, vitamin D status, and multiple sclerosis.

\section{Material and methods}

This was an observational, retrospective, casecontrol study including 107 patients with MS and 133 healthy subjects. Patients and controls were recruited from 2013 to 2016 from the department of Experimental Biomedicine and Neuroscience,

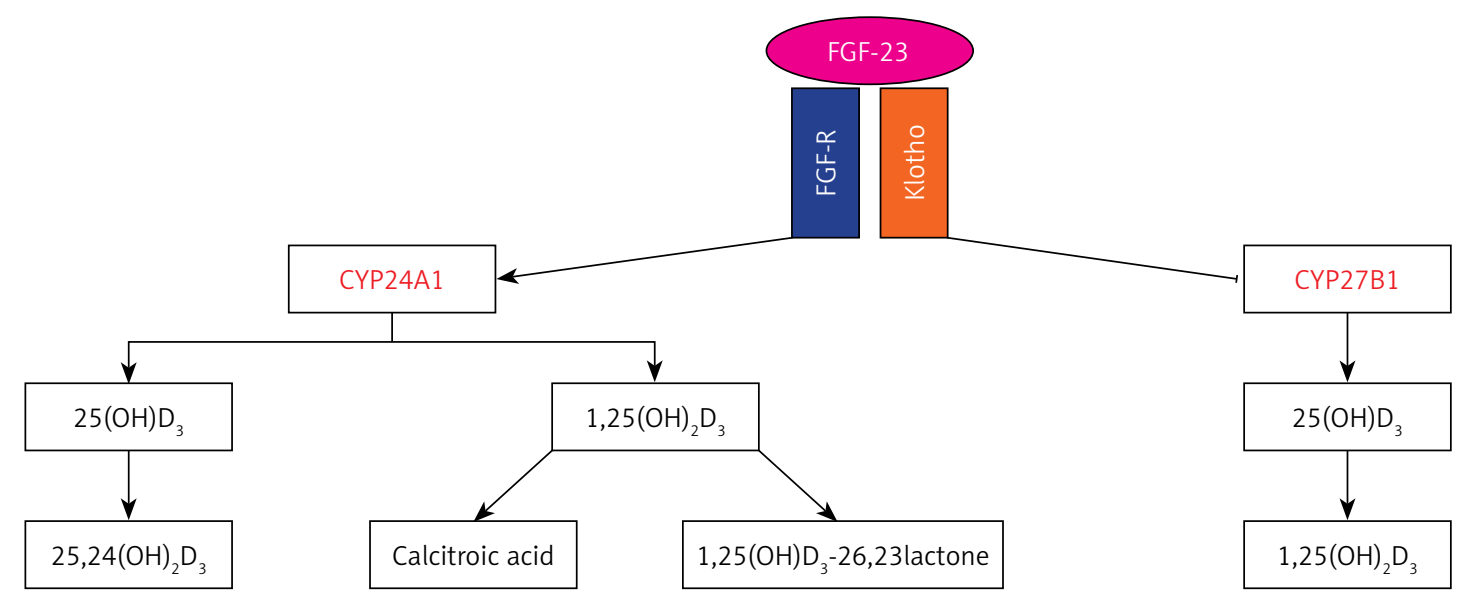

Figure 1. Axis Klotho/FGF-23/vitamin D 
University of Palermo, and from the Unit of Transfusion Medicine of Villa Sofia-Cervello of Palermo. An expert neurologist made the diagnosis of multiple sclerosis according to revised McDonald criteria [39]. The neurological status of patients was assessed using Kurtzke's Expanded disability Status Scale (EDSS), the most common clinical scoring system, ranging from 0 (normal) to 10 (death due to MS) in half-point increments [40]. The progression of disability was assessed using the Multiple Sclerosis Severity Score (MSSS) [41]. The annualised relapse rate (ARR) was calculated in the year prior the genotyping.

The research institute's committee on human research approved the study protocol. All participants gave their written, informed consent.

MS patients comprised 26 men and 81 women with a mean age $39.8 \pm 9.9$ years. Controls were 70 men and 63 women with a mean age of $44 \pm 9.9$ years. Table I shows the demographic and clinical characteristics of study groups.

All samples were genotyped by Real-Time allelic discrimination TaqMan assay (Applied Biosystems). Genomic DNA was purified from $200 \mu \mathrm{l}$ of whole peripheral blood using the QIAamp blood minikit (Qiagen, Valencia, CA, USA). DNA samples were quantified by spectrophotometric determination; aliquots of DNA were stored at $-20^{\circ} \mathrm{C}$ for subsequent analysis. We selected two Single Nucleotide Polymorphisms (SNPS) in KLOTHO, the rs 1207568 (G-395A) in the promoter region and the rs9536314 (F352V) in exon 2. Genotyping for rs1207568 and rs9536314 was carried out by the Taqman SNP genotyping allelic discrimination method on a 7500 real-time PCR system. The PCR reaction mix consisted of $25 \mathrm{ng}$ of DNA, $5 \mu \mathrm{l}$ TaqMan Genotyping Master Mix, and $0.25 \mu$ l genotyping assay mix and distilled water for a final volume of $20 \mu \mathrm{l}$. Cycling conditions for amplifica-

Table I. Demographic and clinical characteristics of patients and controls

\begin{tabular}{|lcc|}
\hline Parameter & $\begin{array}{c}\text { Cases } \\
(n=107)\end{array}$ & $\begin{array}{c}\text { Controls } \\
(n=133)\end{array}$ \\
\hline Age [years] & $39.8 \pm 9.9$ & $44 \pm 9.9^{*}$ \\
\hline Sex, $n$ (male/female) & $26 / 81$ & $70 / 63$ \\
\hline Disease duration [years] & $11.6 \pm 9.8$ & - \\
\hline Age of MS onset [years] & $28.0 \pm 7.9$ & - \\
\hline MS-type (n) RR/SP/PP & $92 / 14 / 1$ & - \\
\hline EDSS & $3.0 \pm 2.2$ & - \\
\hline MSSS & $3.8 \pm 2.7$ & - \\
\hline ARR & $1.25 \pm 0.96$ & - \\
\hline
\end{tabular}

Data are shown as: mean $\pm S D .{ }^{*} p<0.05$. EDSS - Expanded Disability Status Scale, MSSS - Multiple Sclerosis Severity Score, ARR annualised relapse rate. tion were $60^{\circ} \mathrm{C}$ for $30 \mathrm{~s}, 95^{\circ} \mathrm{C}$ for $10 \mathrm{~min}, 40$ cycles as follows: $95^{\circ} \mathrm{C}$ for $15 \mathrm{~s}$ and $60^{\circ} \mathrm{C}$ for $1 \mathrm{~min}$, and a final step at $60^{\circ} \mathrm{C}$ for $30 \mathrm{~s}$ (Applied Biosystems).

$25(\mathrm{OH}) \mathrm{D}_{3}$ levels were measured on serum of both patients and controls. Serum tubes were centrifuged immediately after the collection, and serum was stored at $-20^{\circ} \mathrm{C}$ until the analysis. $25(\mathrm{OH}) \mathrm{D}_{3}$ levels were quantified using a Chromosystem reagent kit (Chromsystems Instruments \& Chemicals) on an isocratic high-performance liquid chromatography (HPLC) system with a UV detector. In accordance with the recommendation of the Institute of Medicine [42], optimal serum $25(\mathrm{OH}) \mathrm{D}_{3}$ levels were defined as $>30 \mathrm{ng} / \mathrm{ml} ; 20-$ $30 \mathrm{ng} / \mathrm{ml}$ and $<20 \mathrm{ng} / \mathrm{ml}$ indicated vitamin D insufficiency and deficiency, respectively.

\section{Statistical analysis}

Statistical analysis was performed using SPSS software (version 13.0). All genotypes were tested for Hardy-Weinberg equilibrium using $\chi^{2}$ test. Allelic and genotypic frequencies of rs 1207568 and rs9536314 were compared between patients and controls by Fisher's exact test. Quantitative results are expressed as the mean \pm standard deviation. A $p$-value $<0.05$ was considered statistically significant.

\section{Results}

The genotypic frequencies of rs1207568 and rs9536314 were found to be in Hardy-Weinberg equilibrium in both study groups. Genotypic and allelic frequency distributions of both SNPs are displayed in Table II. We did not find associations between alleles and genotypes and multiple sclerosis. Furthermore, no significant differences

Table II. Association analysis of Klotho polymorphisms in MS patients and controls

\begin{tabular}{|lcc|}
\hline Polymorphisms & $\begin{array}{c}\text { MS patients } \\
(n=107)\end{array}$ & $\begin{array}{c}\text { Controls } \\
(n=133)\end{array}$ \\
\hline rs9536314: & $80(75 \%)$ & $93(70 \%)$ \\
\hline TT & $24(22 \%)$ & $35(26 \%)$ \\
\hline GT & $3(3 \%)$ & $5(4 \%)$ \\
\hline GG & $30(14 \%)$ & $45(17 \%)$ \\
\hline rs $1207568:$ & $184(86 \%)$ & $221(83 \%)$ \\
\hline GG & $74(69 \%)$ & $84(63 \%)$ \\
\hline AG & $30(28 \%)$ & $42(32 \%)$ \\
\hline AA & $3(3 \%)$ & $7(5 \%)$ \\
\hline G & $178(83 \%)$ & $210(79 \%)$ \\
\hline A & $36(17 \%)$ & $56(21 \%)$ \\
\hline
\end{tabular}

P-value $>0.05$. 


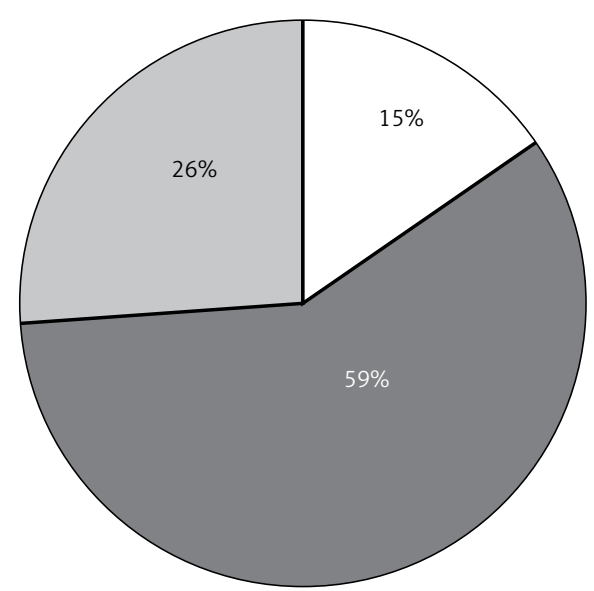

Figure 2. Vitamin D status in multiple sclerosis patients

$\square$ Sufficiency $\square$ Insufficiency $\square$ Deficiency

between MS patients and controls were detected using dominant and recessive genetic models (data not shown). Among MS patients, the analysis of the effect of the SNPs on age of disease onset, EDSS, MSSS, and ARR did not reveal any effect of them on disease course. As previously shown [31, 32], we found that serum $25(\mathrm{OH}) \mathrm{D}_{3}$ levels were significantly lower in MS patients than in controls $(21.8 \pm 7.2 \mu \mathrm{g} / \mathrm{l}$ and $39.1 \pm 9.3 \mu \mathrm{g} / \mathrm{l}$, respectively; $p<0.001)$. In particular, vitamin $\mathrm{D}$ insufficiency was prevalent in MS patients (59\%); $26 \%$ had vitamin D deficiency, and only $15 \%$ had optimal levels (Figure 2). Interestingly, when stratifying MS patients according to SNPs, for rs1207568 we found a trend toward decreased serum $25(\mathrm{OH}) \mathrm{D}_{3}$ levels in $A G$ and AA vs. GG patients (AG + AA $20.5 \pm 6.3 \mu \mathrm{g} / \mathrm{l}$; GG $22.5 \pm 7.5 \mu \mathrm{g} / \mathrm{l}, p=0.07)$; AA patients had the lowest $25(\mathrm{OH}) \mathrm{D}_{3}$ levels $(17.6 \pm 8 \mu \mathrm{g} / \mathrm{l})(p>0.05)$ (Figure 3).

\section{Discussion}

In order to better understand how genetics can influence vitamin D metabolism in MS patients, we evaluated the impact of two polymorphisms of Klotho, one regulatory (rs1207568) and one functional ( $r$ 95536314), in relation to serum $25(\mathrm{OH}) \mathrm{D}_{3}$ levels in patients with multiple sclerosis and healthy subjects; both polymorphisms have never been studied in multiple sclerosis. Our findings revealed no association of both Klotho polymorphisms with MS susceptibility and severity. Remarkably, MS patients harbouring the A allele (mutant) of rs 1207568 - both in homozygosis and in heterozygosis - had lower serum $25(\mathrm{OH}) \mathrm{D}_{3}$ levels than GG patients.

Klotho is a multifunctional protein, which plays a pivotal role in vitamin D metabolism [43]. In vivo studies showed that KLOTHO knockout mouse had severe hypervitaminosis $D$, which was rescued by

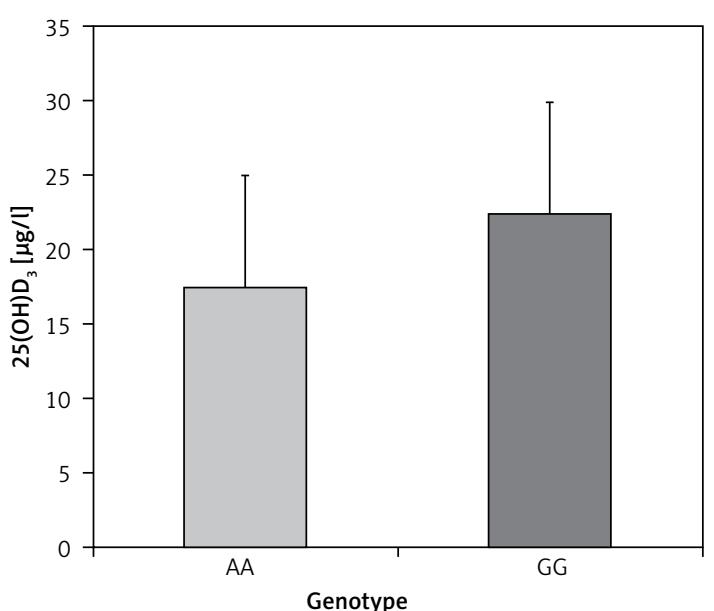

Figure 3. $25(\mathrm{OH}) \mathrm{D}_{3}$ levels in MS patients stratified according to rs1207568 genotype

$A A$ - mutant, GG - wildtype.

vitamin D restriction $[44,45]$. The increase of vitamin $D$ levels in Klotho-deficient mice was a consequence of the increased activity of CYP27B1 and reduced activity of CYP24A1, which are physiologically regulated by Klotho [46].

Klotho gene maps on chromosome 13q12, and it consist of five exons and four introns [47]. GWAS studies have identified polymorphisms in both coding and non-coding regions of the Klotho gene associated with increased risk of diseases such as diabetes and cardiovascular diseases [48-51]. To date, no data are available regarding the role of the Klotho polymorphisms in MS risk. The Klotho SNPs investigated in this study, namely rs 1207568 and rs9536314, have been selected from literature for their functional role in altering protein product (rs1207568) or amino acid (rs9536314). Both SNPs have been associated with an alteration of levels or catalytic activity of Klotho. The SNP rs9536314 is a missense variant and belongs to the KL-VS haplotype. The latter represents a functional variant composed of six SNPs in perfect linkage disequilibrium and spans exon 2 and its flanking sequence [52]. Among these SNPs, the rs9536314 and the rs9527025 result in amino acid substitution - F352V and C370S, respectively. "KL-VS" alludes to the $V$ and $S$ substitution of these two SNPs. The SNP rs9536314 can be used to evaluate the entire haplotype because all six SNPs are in linkage disequilibrium.

The rs1207568 (G-395A) is one of the SNPs located in the promoter region of the KLOTHO gene, near the 5'UTR [53]. In vitro studies reported that the rs1207568 is associated with a higher promoter activity [54] upregulating its expression. Hao et al. hypothesised that this variant could enhance the levels or activity of Klotho [55]. The KL-VS variant, instead, induces an increase of the catalytic activity of Klotho. Consequently, both genetic 
variants could be associated with a reduced activation of $25(\mathrm{OH}) \mathrm{D}_{3}$ and an increased degradation of both $25(\mathrm{OH}) \mathrm{D}_{3}$ and $1,25(\mathrm{OH})_{2} \mathrm{D}_{3}$. Indeed, Klotho induces the down-regulation of CYP27B1, the vitamin D-activating enzyme, and the up-regulation of CYP24A1, the vitamin D-deactivating enzyme. However, functional studies are mandatory to support this hypothesis.

Ellidag et al. showed an alteration of the axis Klotho/FGF-23/vitamin D in MS patients and underlined its importance on the pathogenesis of the disease. In particular, they found higher levels of Klotho and lower levels of $25(\mathrm{OH}) \mathrm{D}_{3}$ in MS patients than in controls [37]. However, the influence of Klotho variants on vitamin $D$ metabolism has never been investigated in MS patients.

Previously, we explored the association among SNPs in several genes involved in vitamin D metabolism, multiple sclerosis, and vitamin D status, revealing a role of genetic variants of VDR, CYP2R1, and CYP24A1 in MS risk and progression [31, 32, $56,57]$. The findings of the present study failed to identify a role of Klotho in either the genetic susceptibility or the progression of multiple sclerosis. Of note, we found that the rs 1207568 is associated with reduced serum $25(\mathrm{OH}) \mathrm{D}_{3}$ levels.

Our study has some limitations, including the small sample and the case-control study design. Thus, we cannot rule out the role of Klotho in MS risk, and large-scale studies are needed to address this.

In conclusion, our findings did not identify a role of genetic variants of Klotho in MS risk and progression.

\section{Acknowledgments}

Concetta Scazzone and Luisa Agnello have contributed equally to the study.

\section{Conflict of interest}

The authors declare no conflict of interest.

\section{References}

1. Kobelt G, Thompson A, Berg J, Gannedahl M, Eriksson J; MSCOI Study Group; European Multiple Sclerosis Platform. New insights into the burden and costs of multiple sclerosis in Europe. Mult Scler 2017; 23: 1123-36.

2. Ascherio A, Munger KL. Epidemiology of multiple sclerosis: from risk factors to prevention-an update. Semin Neurol 2016; 36: 103-14.

3. Sintzel MB, Rametta M, Reder AT. Vitamin D and multiple sclerosis: a comprehensive review. Neurol Ther 2018; 7: 59-85.

4. Littlejohns TJ, Henley WE, Lang IA, et al. Vitamin D and the risk of dementia and Alzheimer disease. Neurology 2014; 83: 920-8

5. Wang X, Zhang S, Lin F, et al. Elevated galectin-3 levels in the serum of patients with Alzheimer's disease. Am J Alzheimers Dis Other Demen 2015; 30: 729-32.
6. Gao O, Fan Y, Mu LY, et al. S100B and ADMA in cerebral small vessel disease and cognitive dysfunction. J Neurol Sci 2015; 354: 27-32.

7. Guo LH, Alexopoulos P, Perneczky R. Heart-type fatty acid binding protein and vascular endothelial growth factor: cerebrospinal fluid biomarker candidates for Alzheimer's disease. Eur Arch Psychiatry Clin Neurosci 2013; 263: 553-60.

8. Agnello L, Bivona G, Lo Sasso B, et al. Galectin-3 in acute coronary syndrome. Clin Biochem 2017; 50: 797-803.

9. Zinellu A, Sotgia S, Porcu P, et al. Carotid restenosis is associated with plasma ADMA concentrations in carotid endarterectomy patients. Clin Chem Lab Med 2011; 49: 897-901.

10. Bivona G, Agnello L, Ciaccio M. Vitamin D and immunomodulation: is it time to change the reference values? Ann Clin Lab Sci 2017; 47: 508-10.

11. Giulia B, Luisa A, Concetta S, Bruna LS, Chiara B, Marcello C. Procalcitonin and community-acquired pneumonia (CAP) in children. Clin Chim Acta 2015; 451: 215-8.

12. Agnello L, Bivona G, Novo G, et al. Heart-type fatty acid binding protein is a sensitive biomarker for early $\mathrm{AMI}$ detection in troponin negative patients: a pilot study. Scand J Clin Lab Invest 2017; 77: 428-32.

13. Dziedzic EA, Gąsior JS, Pawłowski M, et al. Vitamin D level is associated with severity of coronary artery atherosclerosis and incidence of acute coronary syndromes in non-diabetic cardiac patients. Arch Med Sci 2019; 15: 359-68.

14. Ciebiera $M$, Włodarczyk $M$, Słabuszewska-Jóźwiak $A$, Ciebiera M, Nowicka G, Jakiel G. Vitamin D serum levels in women using contraception containing drospirenone - a preliminary study. Arch Med Sci 2019; 15: 554-7.

15. Faridi KF, Lupton JR, Martin SS, et al. Vitamin D deficiency and non-lipid biomarkers of cardiovascular risk. Arch Med Sci 2017; 13: 732-7.

16. Ilinčić B, Stokić E, Stošić Z, et al. Vitamin D status and circulating biomarkers of endothelial dysfunction and inflammation in non-diabetic obese individuals: a pilot study. Arch Med Sci 2017; 13: 53-60.

17. Ascherio A, Munger KL, Simon KC. Vitamin D and multiple sclerosis. Lancet Neurol 2010; 9: 599-612.

18. Acheson ED, Bachrach CA. The distribution of multiple sclerosis in U. S. Veterans by birthplace. Am J Hyg 1960; 72: 88-99.

19. Simpson S Jr, Der Mei IV, Taylor B. The role of vitamin D in multiple sclerosis: biology and biochemistry, epidemiology and potential roles in treatment. Med Chem 2018; 14: $129-43$.

20. Simpson S Jr, Taylor BV, van der Mei I. The role of epidemiology in MS research: past successes, current challenges and future potential. Mult Scler 2015; 21: 969-77.

21. Khosravi-Largani M, Pourvali-Talatappeh P, Rousta AM, et al. A review on potential roles of vitamins in incidence, progression, and improvement of multiple sclerosis. eNeurologicalSci 2018; 10: 37-44.

22. Breuer J, Loser K, Mykicki N, Wiendl H, Schwab N. Does the environment influence multiple sclerosis pathogenesis via UVB light and/or induction of vitamin D? J Neuroimmunol 2019; 329: 1-8.

23. Munger KL, Ascherio A. Prevention and treatment of MS: studying the effects of vitamin D. Mult Scler 2011; 17: $1405-11$.

24. Dankers W, Colin EM, van Hamburg JP, Lubberts E. Vitamin D in autoimmunity: molecular mechanisms and therapeutic potential. Front Immunol 2017; 7: 697. 
25. Pierrot-Deseilligny C, Souberbielle JC. Vitamin D and multiple sclerosis: an update. Mult Scler Relat Disord 2017; 14: 35-45.

26. Imga NN, Berker D, Can B, Guler. The effects of three regimens of cholecalciferol (vitamin D3) supplementation on vitamin D deficiency in non-obese and obese females. Arch Med Sci Atheroscler Dis 2018; 3: e60-7.

27. Jerzyńska J, Stelmach W, Rychlik B, et al. Clinical and immunological effects of vitamin D supplementation during the pollen season in children with allergic rhinitis. Arch Med Sci 2018; 14: 122-31.

28. Bivona G, Agnello L, Ciaccio M. The immunological implication of the new vitamin $D$ metabolism. Cent Eur J Immunol 2018; 43: 331-4.

29. Mokry LE, Ross S, Ahmad OS, et al. Vitamin D and risk of multiple sclerosis: a Mendelian Randomization Study. PLoS Med 2015; 12: e1001866.

30. Rhead B, Bäärnhielm M, Gianfrancesco $M$, et al. Mendelian randomization shows a causal effect of low vitamin D on multiple sclerosis risk. Neurol Genet 2016 2: e97.

31. Agnello L, Scazzone C, Lo Sasso B, et al. VDBP, CYP27B1, and 25-hydroxyvitamin $D$ gene polymorphism analyses in a group of sicilian multiple sclerosis patients. Biochem Genet 2017; 55: 183-92.

32. Agnello L, Scazzone C, Lo Sasso B, et al. CYP27A1, CYP24A1, and RXR-alpha polymorphisms, vitamin D, and multiple sclerosis: a pilot study. J Mol Neurosci 2018; 66: 77-84.

33. Kuro-o M, Matsumura Y, Aizawa $\mathrm{H}$, et al. Mutation of the mouse klotho gene leads to a syndrome resembling ageing. Nature 1997; 390: 45-51.

34. Matsumura Y, Aizawa H, Shiraki-lida T, Nagai R, Kuro-o M, Nabeshima Y. Identification of the human klotho gene and its two transcripts encoding membrane and secreted klotho protein. Biochem Biophys Res Commun 1998; 242: 626-30.

35. Berridge MJ. Vitamin D cell signalling in health and disease. Biochem Biophys Res Commun 2015; 460: 53-71.

36. Tayyar AT, Tayyar A, Kozali S, et al. Evaluation of FGF-19 and beta-klotho as biomarkers in patients with intrahepatic cholestasis of pregnancy. Arch Med Sci 2019; 15: 113-9.

37. Ellidag HY, Yilmaz N, Kurtulus F, et al. The three sisters of fate in multiple sclerosis: Klotho (Clotho), fibroblast growth factor-23 (Lachesis), and vitamin D (Atropos). Ann Neurosci 2016; 23: 155-61.

38. Christakos S, Dhawan P, Verstuyf A, Verlinden L, Carmeliet G. Vitamin D: metabolism, molecular mechanism of action, and pleiotropic effects. Physiol Rev 2016; 96 : 365-408.

39. Thompson AJ, Banwell BL, Barkhof F, et al. Diagnosis of multiple sclerosis: 2017 revisions of the McDonald criteria. Lancet Neurol 2018; 17: 162-73.

40. Kurtzke JF. Rating neurologic impairment in multiple sclerosis: an expanded disability status scale (EDSS). Neurology 1983; 33: 1444-52.

41. Roxburgh RH, Seaman SR, Masterman T, et al. Multiple sclerosis severity score: using disability and disease duration to rate disease severity. Neurology 2005; 64: 1144-51.

42. Ross AC, Manson JE, Abrams SA, et al. The 2011 report on dietary reference intakes for calcium and vitamin $D$ from the Institute of Medicine: what clinicians need to know. J Clin Endocrinol Metab 2011; 96: 53-8.

43. Dalton GD, Xie J, An SW, Huang CL. New insights into the mechanism of action of soluble Klotho. Front Endocrinol (Lausanne) 2017; 8: 323.
44. Kosakai A, Ito D, Nihei Y, et al. Degeneration of mesencephalic dopaminergic neurons in klotho mouse related to vitamin D exposure. Brain Res 2011; 1382: 109-17.

45. Kuro-o M. Klotho as a regulator of fibroblast growth factor signaling and phosphate/calcium metabolism. Curr Opin Nephrol Hypertens 2006; 15: 437-41.

46. Tsujikawa H, Kurotaki Y, Fujimori T, Fukuda K, Nabeshima Y. Klotho, a gene related to a syndrome resembling human premature aging, functions in a negative regulatory circuit of vitamin D endocrine system. Mol Endocrinol 2003; 17: 2393-403.

47. $\mathrm{Xu} \mathrm{Y}$, Sun Z. Molecular basis of Klotho: from gene to function in aging. Endocr Rev 2015; 36: 174-93.

48. Rhee EJ, Oh KW, Lee WY, et al. The differential effects of age on the association of KLOTHO gene polymorphisms with coronary artery disease. Metabolism 2006; 55 : 1344-51.

49. Shimoyama Y, Nishio K, Hamajima N, Niwa T. KLOTHO gene polymorphisms G-395A and C1818T are associated with lipid and glucose metabolism, bone mineral density and systolic blood pressure in Japanese healthy subjects. Clin Chim Acta 2009; 406: 134-8.

50. Keles N, Dogan B, Kalcik M, et al. Is serum klotho protective against atherosclerosis in patients with type 1 diabetes mellitus? J Diabetes Complications 2016; 30: 126-32.

51. Donate-Correa J, Martín-Núñez E, Martínez-Sanz R, et al. Influence of klotho gene polymorphisms on vascular gene expression and its relationship to cardiovascular disease. J Cell Mol Med 2016; 20: 128-33.

52. Arking DE, Krebsova A, Macek M Sr, et al. Association of human aging with a functional variant of klotho. Proc Natl Acad Sci USA 2002; 99: 856-61.

53. Hao Q, Wang Y, Ding X, et al. G-395A polymorphism in the promoter region of the KLOTHO gene associates with frailty among the oldest-old. Sci Rep 2018; 8: 6735.

54. Wang HL, Xu Q, Wang Z, et al. A potential regulatory single nucleotide polymorphism in the promoter of the Klotho gene may be associated with essential hypertension in the Chinese Han population. Clin Chim Acta 2010; 411: 386-90.

55. Hao Q, Ding X, Gao L, Yang M, Dong B.G-395A polymorphism in the promoter region of the KLOTHO gene associates with reduced cognitive impairment among the oldest old. Age (Dordr) 2016; 38: 7.

56. Scazzone C, Agnello L, Ragonese P, et al. Association of CYP2R1 rs10766197 with MS risk and disease progression. J Neurosci Res 2018; 96: 297-304.

57. Agnello L, Scazzone C, Ragonese P, et al. Vitamin D receptor polymorphisms and 25-hydroxyvitamin D in a group of Sicilian multiple sclerosis patients. Neurol Sci 2016; 37: 261-7. 